\title{
Libros de artista en la colección de la Universitat Politècnica de València. Art books in the collection of the Universitat Politècnica de València.
}

\author{
Antonio Alcaraz Mira \\ Profesor Titular, Facultad de BBAA \\ Universitat Politècnica de València, \\ España. \\ aalcaram@dib.upv.es
}

Recibido 30/11/2016

Aceptado 07/01/2017
Revisado 05/01/2017

Publicado 01/07/2017

\section{Resumen}

Los principales museos y centros de arte contemporáneo han completado sus colecciones de arte con documentación y publicaciones de artista, no sólo debido a la relevancia que este material posee de cara a ofrecer una lectura completa del arte contemporáneo, sino también porque se trata de obras muy importantes en el conjunto de la producción artística de autores internacionalmente reconocidos, como Ruscha, Dieter Roth, Boltanski, Hans-Peter Feldmann, Joan Brossa, Antoni Muntadas, Isidoro Valcárcel Medina o Francesc Torres.

\section{Abstract}

The main museums and contemporary art centers have completed their collections of art with documentation and artist publications, not only because of the relevance that this material possesses in order to offer a complete reading of contemporary art, but also because we are talking about very Important work in the artistic production of internationally recognized authors, such as Ruscha, Dieter Roth, Boltanski, Hans-Peter Feldmann, Joan Brossa, Antoni Muntadas, Isidoro Valcárcel Medina and Francesc Torres.

Para citar este artículo

Alcaraz Mira. A, (2017). Libros de artista en la colección de la Universidad Politécnica de Valencia. Tercio Creciente 13, págs. 97-108. https://dx.doi.org/10.17561/rtc.mextra1.6 
El Ensayo pretende ofrecer información sobre los contenidos de la colección singular, incluida en el Fondo de Arte de una Universidad pública, utilizando como referencias las diferentes secciones de la exposición que se realizó en 2016 en la sala de exposiciones del edificio de Rectorado UPV, bajo el título Salt de Pàgina.
The Essay aims to provide information on the contents of the singular collection, included in the Art Fund of a state University, using as reference the different sections of the exhibition that was held in 2016 in the exhibition hall of the Rectorado UPV building, under The title Salt de Pàgina.

Palabras clave / Keywords

Libro de artista, Arte contemporáneo, Publicaciones especiales, Revistas experimentales, Libro ilustrado, Poesía visual.

Artist book, Contemporary art, Special publications, Experimental magazines, Illustrated book, Visual poetry.

Para citar este artículo

Alcaraz Mira. A, (2017). Libros de artista en la colección de la Universidad Politécnica de Valencia. Tercio Creciente 13, págs. 97-108. https://dx.doi.org/10.17561/rtc.mextra1.6 


\section{Introducción}

Los principales museos y centros de arte contemporáneo han completado sus colecciones de arte con documentación y publicaciones de artista, no sólo debido a la relevancia que este material posee de cara a ofrecer una lectura completa del arte contemporáneo, sino también porque se trata de obras muy importantes en el conjunto de la producción artística de autores internacionalmente reconocidos, como Ruscha, Dieter Roth, Boltanski, Hans-Peter Feldmann, Joan Brossa, Antoni Muntadas, Isidoro Valcárcel Medina o Francesc Torres.

La Colección Libro de Artista de la Universitat Politècnica de València está ubicada en la Biblioteca de la Facultad de Bellas Artes y, en la actualidad, cuenta con más de 1000 ejemplares. Parte del periodo de los años 1960 y atiende tanto al libro de artista como a publicaciones especiales, revistas experimentales, libro ilustrado, poesía visual o cualquier obra realizada por artistas en formato libro.

Se han presentado diferentes exposiciones monográficas que muestran esta colección, la última de ellas tuvo lugar entre los meses de enero y marzo de 2016 en la Sala de Exposiciones de la Universitat Politècnica de València, edificio de Rectorado, bajo el título Salt de Pàgina ${ }^{1}$. La muestra, comisariada por el profesor Antonio Alcaraz, se organizaba entorno a seis recorridos o secciones que intentan presentar algunas de las obras más representativas de esta colección pública perteneciente al Fondo de Arte de la UPV:

\section{Los artistas y el libro a partir de los años 1960. Punto de partida en la colección UPV}

En las primeras décadas del siglo $\mathrm{XX}$-identificadas con el período de las vanguardias- todos los movimientos artísticos trabajaron con la intención de distanciarse del academicismo buscando nuevos medios de expresión y descubriendo en el libro un vehículo ideal para desarrollar sus objetivos. El libro fue transformando la función que ejercía como contenedor de palabras, de ideas y de comunicación, mientras los artistas paulatinamente iban introduciendo otros lenguajes vinculados a las artes plásticas.

La innovación en la arquitectura del libro y la utilización de materiales hasta el momento no relacionados con la edición provocan en el espectador una nueva experiencia que, en ocasiones, puede dejar en segundo plano el contenido del texto, al que llegan a hacer prescindible.

1.-El título Salt de Pàgina (Salto de Pàgina) será cambiado por otro, en caso de itinerar esta exposición, debido a que fue utilizado con anterioridad por el Banco de Sabadell para presentar su colección de libros de artista en exposiciones itinerantes realizadas por diversas ciudades españolas. 
En los movimientos de las vanguardias, el libro desempeñará un papel fundamental para entender y utilizar la escritura, convirtiéndose en soporte de experimentación. Futuristas, dadaístas, constructivistas y surrealistas utilizaron el libro como espacio creativo y encontraron en este medio un sistema económico y de fácil acceso para la difusión de sus obras.

El catálogo, en edición de lujo, de la exposición de Marcel Duchamp, en la Galería Ronny Van de Velde es un buen ejemplo. La publicación recrea sus museos portátiles en la conocida caja de ajedrez e incluye textos de André Breton, una cinta de audio, fotografías y cartas de Duchamp, junto a otros objetos.

Estas características se acentúan a partir de los años 1960 en los que la aparición del movimiento Fluxus utiliza el libro como una forma de expresión con la que documentar sus encuentros, performances o propuestas plásticas, transformando así el concepto de obra original y produciendo multitud de objetos, periódicos, revistas, libros, etc. En estas publicaciones será habitual la participación de varios artistas en la creación de una misma obra, como es el caso de An Anthology, de 1963. La filosofía Fluxus continuó en manos de artistas como John Cage, Nam June Paik, Dieter Roth, Joseph Beuys, Robert Filliou, Dick Higgins, etc.

\section{Libro ilustrado. El texto como punto de partida obligado para el desarrollo del libro}

Si la relación entre texto e imagen aparece con la propia creación del libro o de los primeros documentos gráficos, el libro ilustrado entendido como una colaboración entre un artista y un escritor, en la que la parte gráfica adquiere cierto protagonismo en la publicación, la encontramos ya en la segunda mitad del siglo XIX en Francia, con la aparición del denominado livre d'artiste.

Los libros ilustrados fueron objeto de colección, hecho que provocó que numerosos artistas de prestigio internacional -como Braque, Chagall, Picasso, Rouault, Bonnard, Mallarmé o Manet- se interesaran por participar en las publicaciones, añadiendo a éstas un valor más amplio que el propio contenido que ilustraban. En estos años de transición entre el siglo XIX y el XX destacan las ediciones de Ambroise Vollard, Albert Skira, Daniel-Henry Kahnweiler y, posteriormente, Tériade y Maeght, más en sintonía con el concepto desarrollado por las vanguardias frente al clásico de editores y bibliófilos.

En esta exposición se han seleccionado algunos libros ilustrados con obra gráfica original, numerados y firmados por autores como Carlos Pazos y Ramón de España, Francesc Torres con Frágil es la llama, Miguel Ángel Ríos y Sebastià Miralles, Manuel Rey Fueyo y Juan Manuel Bonet o José Pedro Croft, ilustrando el texto Los trabajos de Persiles y Sigismunda de Miguel de Cervantes.

\section{Sólo imagen. Fotolibro contemporáneo. Algunos artistas del panorama internacional}

Aunque el libro de artista contemporáneo $y$ el fotolibro se desarrollan en la segunda mitad del siglo XX, es evidente que este tipo de prácticas deriva de la situación de rebeldía, inconformismo y cuestionamiento de los valores establecidos en el mundo del arte que plantearon los movimientos de las vanguardias.

Entre los artistas presentes en la colección 

Julio 2017 de la UPV destacan el americano Edward Ruscha y su mítico libro Every Building on the Sunset Strip, editado en 1966. Junto a este autor también cabe mencionar nombres como los de Hans-Peter Feldmann, Richard Hamilton, Bernd y Hilla Becher, Felipe Ehrenberg, Christian Boltanski, Matt Mullican o Peter Piller.

La facilidad de acceso a las nuevas tecnologías, así como la posibilidad de realizar ediciones cortas y económicas, han contribuido al impulso que la edición del libro de artista o las publicaciones especiales han tenido entre las nuevas generaciones. En España destaca la obra de José Emilio Antón, centrada en los libros desde la década de 1970 y que en Edoi, trabajo realizado en 1985, explora las posibilidades abiertas por la electrografía con una serie de collages fotocopiados y coloreados manualmente.

\section{La experimentación poética. Poesía visual y poesía experimental}

Según Clemente Padín, Mallarmé en su libro Un coup de dés jamais n'abolira le hasard inaugura el papel primordial del espacio y lo visual en la poesía de los nuevos tiempos,mediante la integración de lo visual y lo verbal en el poema (y, eventualmente, de lo fónico, si éste fuera leído).

En lo concerniente a poesía visual y poesía experimental, contamos autores considerados pioneros a nivel internacional. Es el caso de Robert Filliou y su libro La cedille qui sourit de 1969, de Edgardo Antonio Vigo con la obra Poemas matemáticos barrocos de 1967, y de Guillermo Deisler, Clemente Padín, Joan Brossa, Bartolomé Ferrando o Antonio Gómez. Asimismo, nuestra colección posee publicaciones colectivas como Texto Poético, Vox, Uni/vers, Biopsia, etc.

\section{Sólo texto... de artista. Escritos y documentos como una forma paralela de expresión artística}

Desde la década de 1960 se extiende por Europa y Estados Unidos la idea de libro como medio artístico y la de libro con función documental, generalizándose la producción de pequeños formatos impresos con medios de reproducción masiva, hecho que fue promovido por artistas vinculados al minimalismo y al arte conceptual. Las nociones de reproductibilidad se intensifican tratando el libro de artista como un producto de masas e intentando desmaterializar el arte de modo que, en muchas instalaciones efímeras, es la publicación el único archivo o documento que permite registrar el proyecto o completar la información de la obra. Algunos de estos artistas utilizarán el lenguaje como la máxima abstracción del arte. Sus escritos y manifiestos serán considerados, en la actualidad, una forma paralela de expresión artística. Entre estos autores destacan Daniel Spoerri con An anecdotedtopography of chance de 1966 y Dokumente de 1971, Ben Porter, Antoni Muntadas, con su obra Documentos. Actividades II-III de 1976, Leopoldo $\mathrm{M}^{\mathrm{a}}$ Panero o Isidoro Valcárcel Medina.

\section{Colecciones experimentales. Explorando los límites del diseño editorial}

En las últimas décadas se ha producido en el mundo editorial una renovación en el ámbito de la experimentación gráfica, concretamente en las ediciones relacionadas con productos de arte. Esto ha posibilitado que surjan editoriales que, compartiendo el impulso por crear proyectos experimentales 
en formato libro, se alejan de los libros convencionales y de las políticas culturales institucionales, proponiendo publicaciones donde los contenidos formales y conceptuales no se hayan condicionados por la demanda del mercado.

En general, suelen ser proyectos editoriales dirigidos por diseñadores, artistas, escritores o teóricos del arte, con nuevos conceptos y fórmulas de edición, que dan lugar a formatos estéticos y textuales muy relacionados con el libro de artista. En este apartado presentamos tres colecciones: Alias, Pusilánime y Lubok.

Alias (México), proyecto del artista Damián Ortega y la editora Sara Schulz, está compuesto por una selección de referencias en su mayoría internacionales, que no habían sido traducidas al español, como Entre el mueble y el inmueble (entre una roca y un lugar sólido) de Jimmie Durham, o ediciones descatalogadas como Para los pájaros de John Cage. Estos libros abarcan desde entrevistas a artistas, textos de éstos sobre su trabajo, ensayos de crítica de arte y catálogos de exposiciones, hasta poesía, cómic y narrativa de artistas. Se trata de un material realizado con un criterio arriesgado que intenta ser adaptado al diseño de colección marcado por Alias.

Pusilánime (Valencia) es un proyecto editorial dirigido por Marta Pina. La iniciativa, autogestionada, mantiene un formato de colección en el que cada artista realiza su propuesta con total libertad de contenido y técnica. En la actualidad la colección se compone de 11 números con una edición de 100 ejemplares que realiza el taller Industrias Lentas, enfocado a la recuperación y experimentación de las distintas técnicas gráficas. Pusilánime toma como referencia los viejos souvenirs turísticos que ofrecían postales de lugares pintorescos. Esas vistas, reunidas en cuadernillos, podían arrancarse para ser enviadas por correo, aunque también podían coleccionarse juntas, como un recuerdo de viaje. Esta colección permite mostrar pequeños proyectos gráficos difíciles de publicar en otros medios.

Lubok (Leipzig) se originó en 2007 a partir del encuentro del artista Christoph Ruckhäberle con el diseñador gráfico y tipógrafo Thomas Siemon. Ambos comparten la fascinación por el libro de artista y el entusiasmo por la edición de proyectos gráficos originales. Imprimen, utilizando exclusivamente linóleos de artistas contemporáneos en el taller Carpe Plumbum, con una prensa plano-cilíndrica de 1958. Las ediciones, entre 300 y 1500 ejemplares, son altas para el género del libro de artista, pero permiten trabajar con precios asequibles que facilitan su difusión a un público amplio. Lubok forma parte de numerosas colecciones de arte gráfico actual, destacando la Biblioteca Nacional Alemana, la Biblioteca Pública de Nueva York o la Biblioteca del Centro Georges Pompidou de París 
Revista de Estudios en Sociedad, Artes y Gestión Cultural

www.terciocreciente.com

http://revistaselectronicas.ujaen.es/index.php/RTC
Monográfico Extraordinario I Julio 2017

Ensayo visual
SSN: 2340-9096

DOI: $10.17561 /$ rtc.mextra1.6

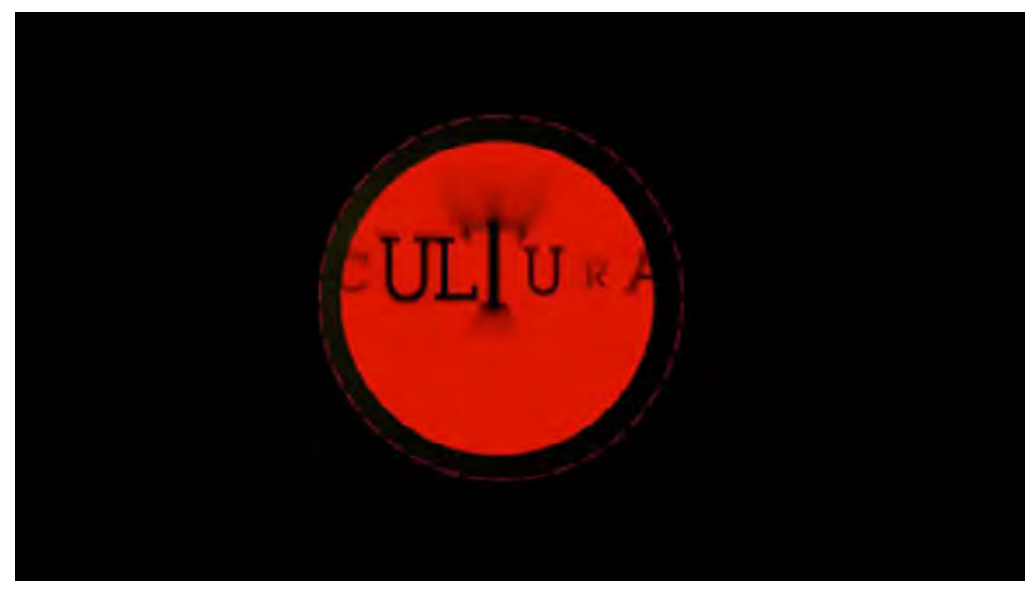

https://youtu.be/4pwVuKJFXyM
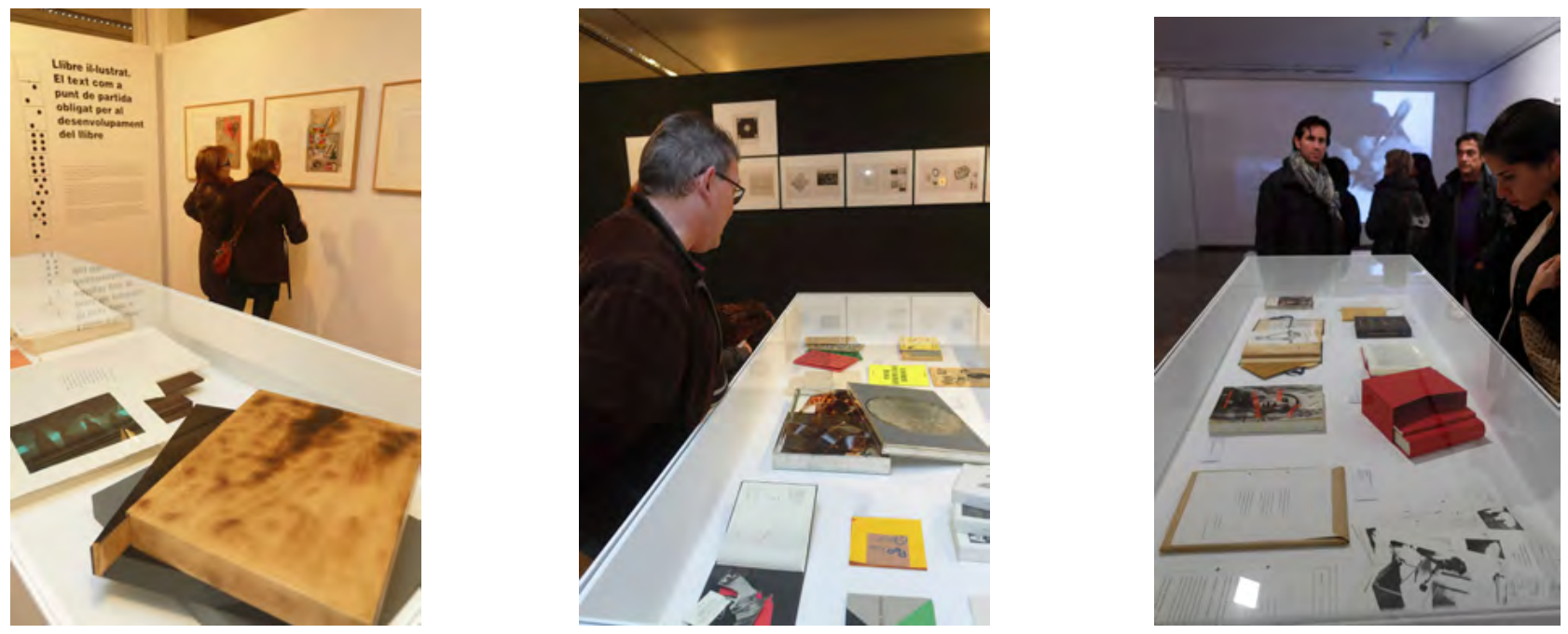
Revista de Estudios en Sociedad, Artes y Gestión Cultural

www.terciocreciente.com

http://revistaselectronicas.ujaen.es/index.php/RTC
Monográfico Extraordinario I

Julio 2017

Ensayo visual
ISSN: $2340-9096$

DOI: $10.17561 /$ rtc.mextra1.6
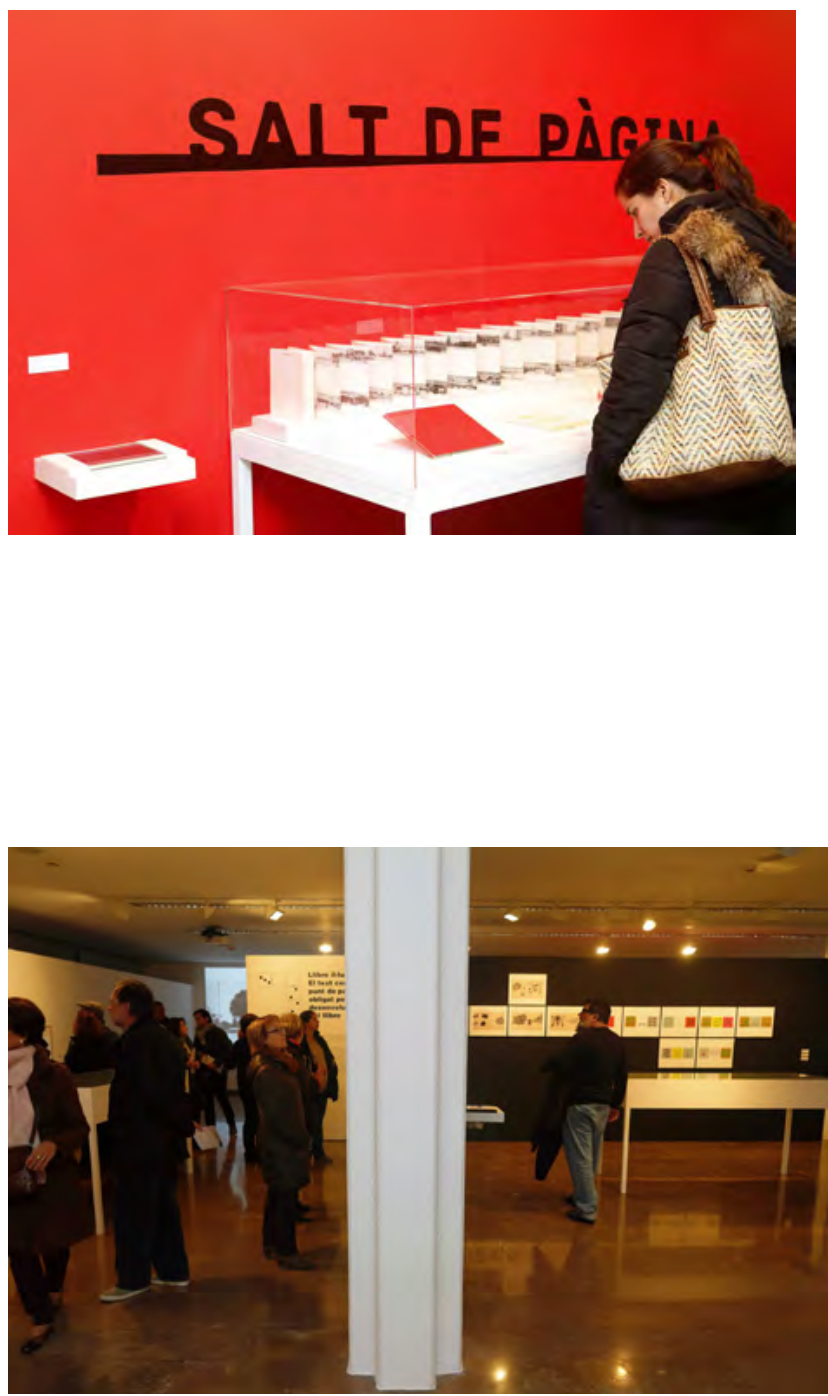
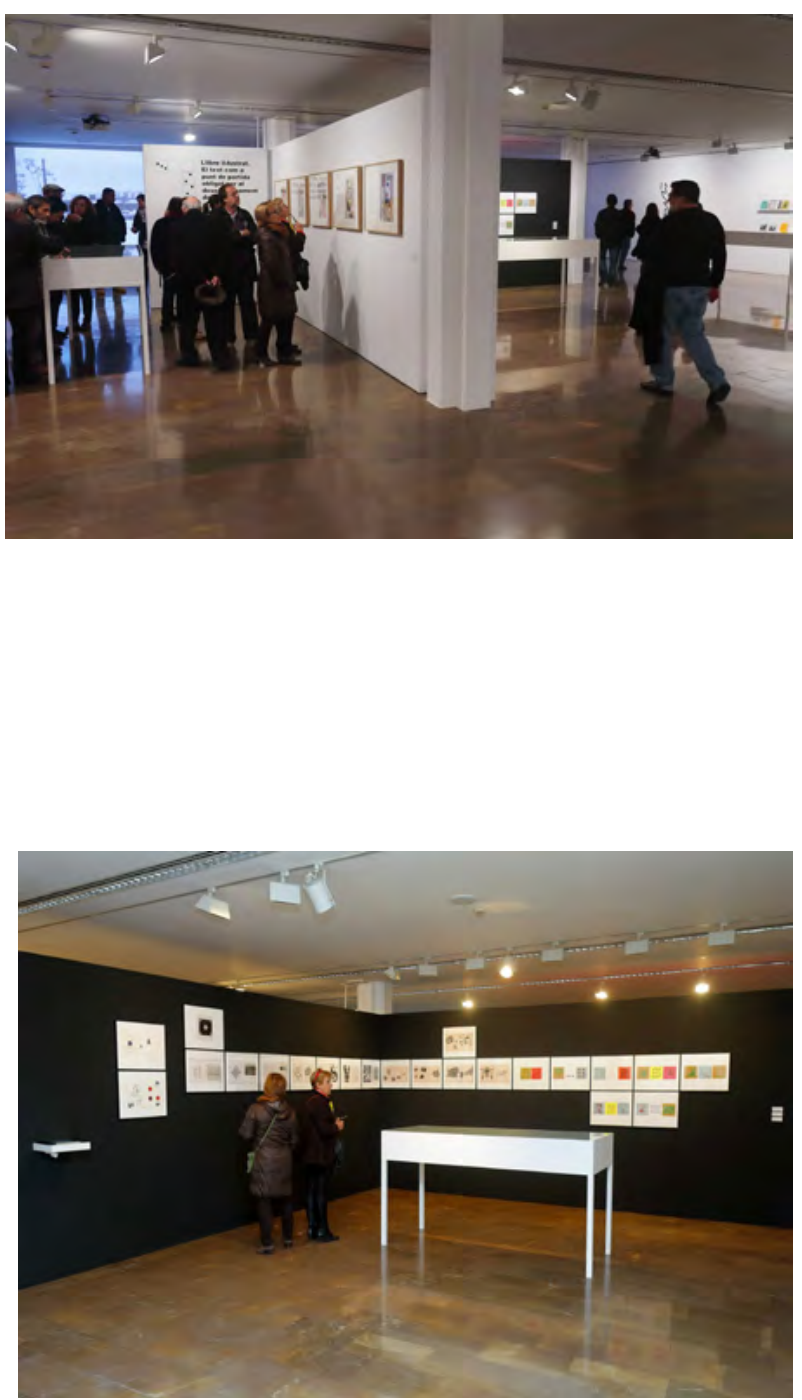
Revista de Estudios en Sociedad, Artes y Gestión Cultural

www.terciocreciente.com

http://revistaselectronicas.ujaen.es/index.php/RTC
Monográfico Extraordinario I Julio 2017

Ensayo visual
DOI: 10.17561/rtc.mextra1.6
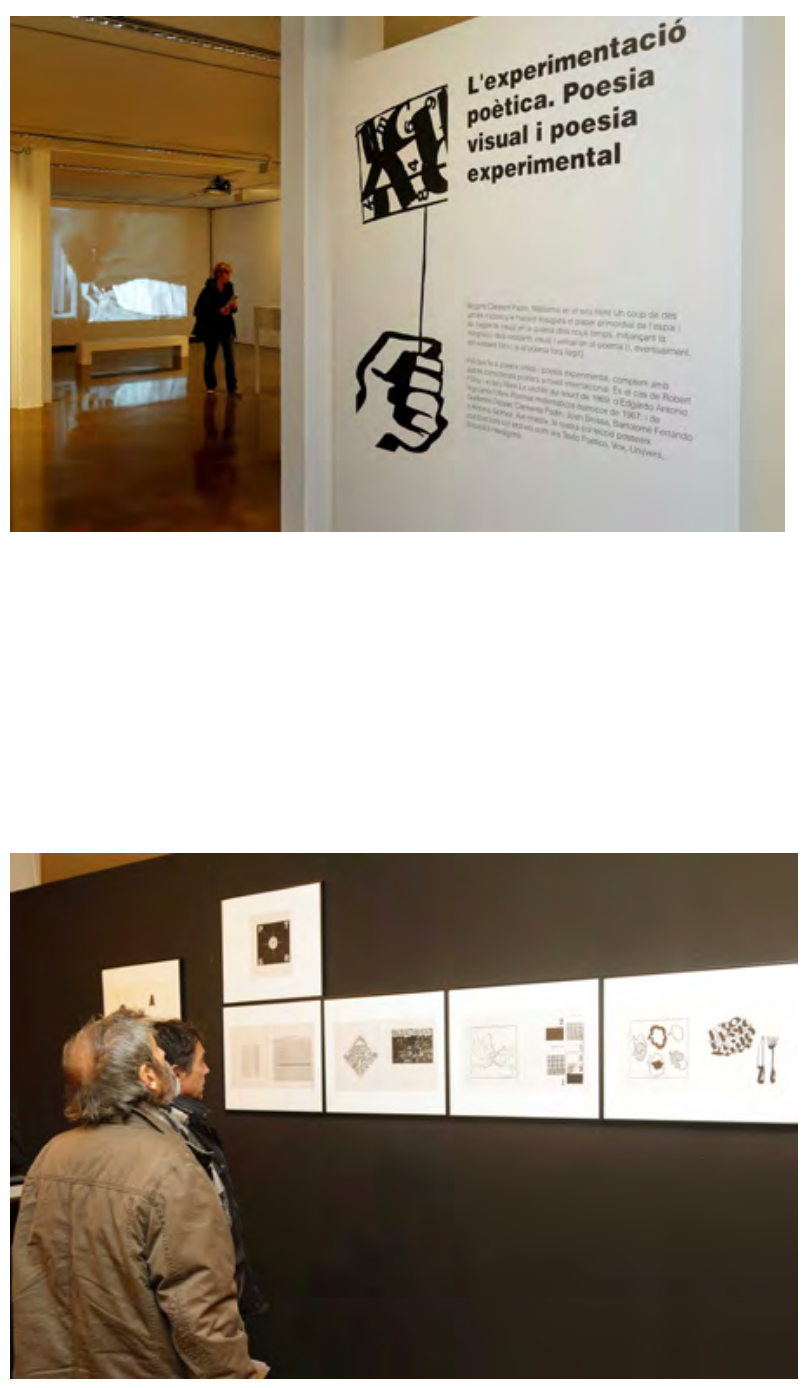
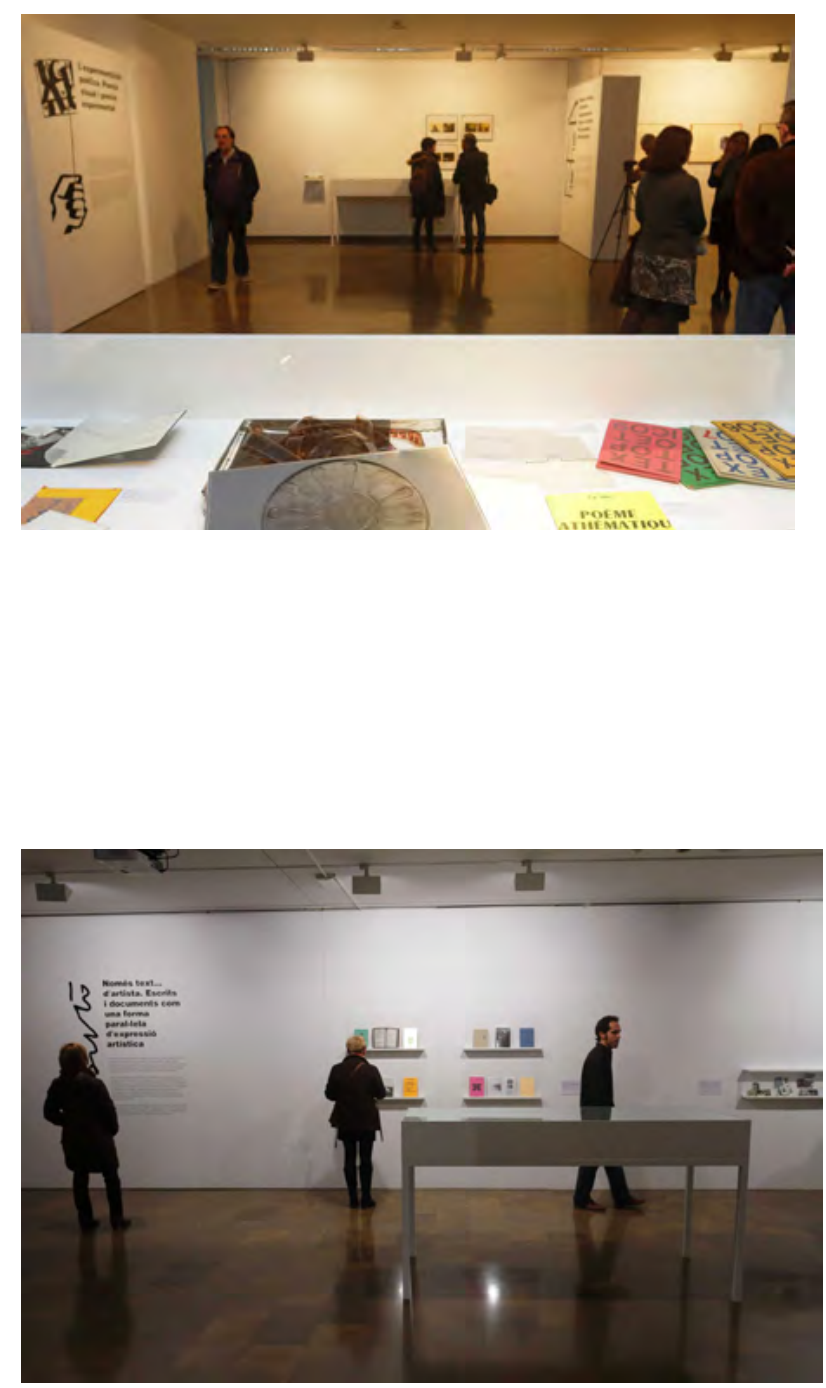
Tercio Creciente

ISSN: 2340-9096

DOI: 10.17561/rtc.mextra1.6
Revista de Estudios en Sociedad, Artes y Gestión Cultural

www.terciocreciente.com

http://revistaselectronicas.ujaen.es/index.php/RTC
Monográfico Extraordinario I

Julio 2017

Ensayo visual
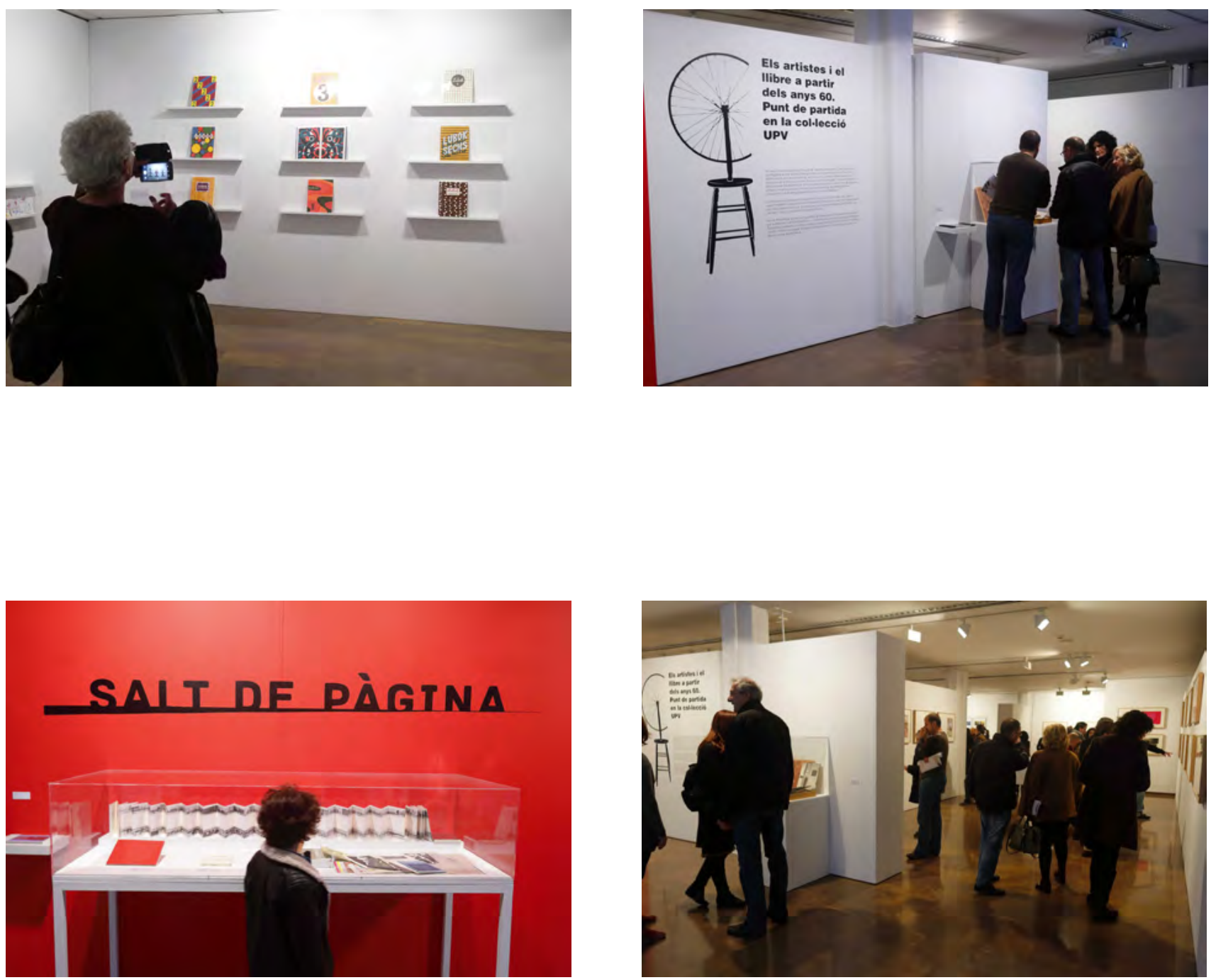
Revista de Estudios en Sociedad, Artes y Gestión Cultural

www.terciocreciente.com

http://revistaselectronicas.ujaen.es/index.php/RTC
Monográfico Extraordinario I Julio 2017

Ensayo visual
SSN: 2340-9096

DOI: $10.17561 /$ rtc.mextra1.6
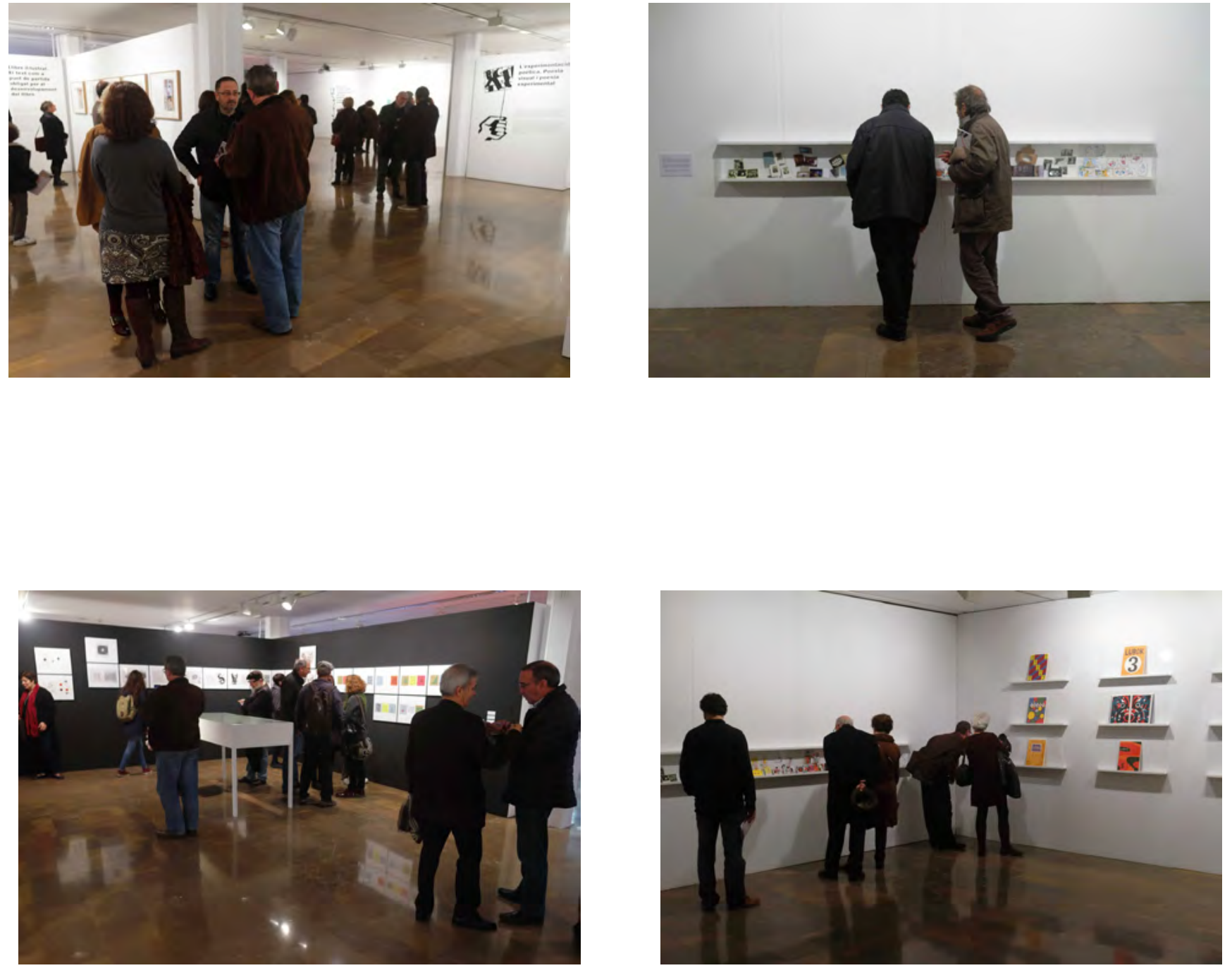


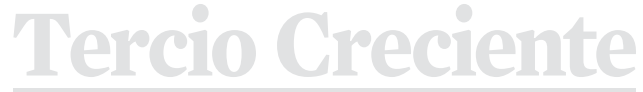

ISSN: 2340-9096

DOI: 10.17561/rtc.mextra1.6
Revista de Estudios en Sociedad, Artes y Gestión Cultural

www.terciocreciente.com

http://revistaselectronicas.ujaen.es/index.php/RTC
Monográfico Extraordinario I

Julio 2017

Ensayo visual
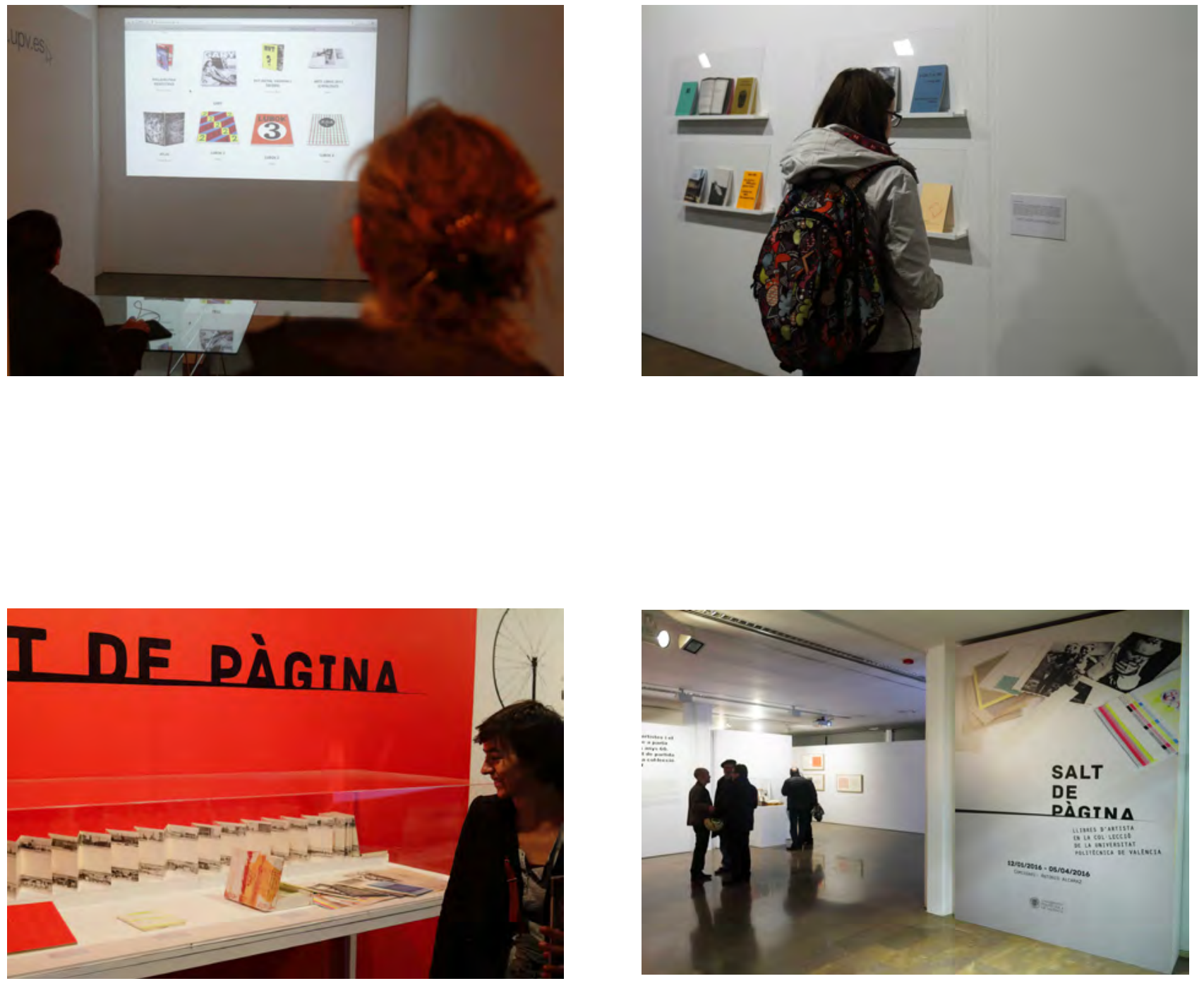